\title{
Regionalization and trends in winter precipitation in the northwestern USA
}

\author{
James A. Miller ${ }^{1, *}$, Gregory B. Goodrich ${ }^{2}$ \\ ${ }^{1}$ Department of Geography, Arizona State University, PO Box 870104, Tempe, Arizona 85287, USA \\ ${ }^{2}$ Department of Geography and Geology, Western Kentucky University, Rm. 31066, 1906 College Heights Boulevard, \\ Bowling Green, Kentucky 42101, USA
}

\begin{abstract}
Recent modeling studies have predicted that while temperature is expected to increase over the next few decades in the Pacific Northwest (PNW), model predictions of winter season precipitation are highly variable. Implications of potential climate change were explored by regionalizing PNW climate. Using rotated Principal Components Analysis (PCA), sub-regions within the PNW were developed for winter season precipitation from 1895-2003. Analyses include synoptic discussions based on trends of the time series of the component scores as well as an examination of the sensitivity to the El Niño/Southern Oscillation (ENSO) and Pacific Decadal Oscillation (PDO) for each sub-region. Four sub-regions during the winter season were created, based on temporal variability of precipitation. While previous studies suggest that there is regional coherence in PNW precipitation, analysis of the time series of the component scores for each sub-region suggests otherwise. Several sub-regions show widely diverging trends in winter season precipitation over the past $30 \mathrm{yr}$, a period that also coincides with significant warming across the PNW. Differences in the sign and strength of correlations between ENSO and the PDO with winter season precipitation occur between the subregions, which further suggests a lack of coherence in the PNW.
\end{abstract}

KEY WORDS: Pacific Northwest · Sub-regional variability · Principal Components Analysis · ENSO PDO $\cdot$ Precipitation $\cdot$ PCA $\cdot$ Teleconnection

Resale or republication not permitted without written consent of the publisher

\section{INTRODUCTION}

An important area of recent research is the prediction of climate change in the Pacific Northwest (PNW). Several investigators have examined the potential impacts of greenhouse gas induced climate change on the natural resources and ecosystems of the PNW (Hamlet \& Lettenmaier 1999, Miles et al. 2000, Mote et al. 2003). Modeling results of 8 General Circulation Models (GCMs) show that while temperature in the PNW is expected to increase, trends regarding winter and summer season precipitation vary widely up or down depending on the GCM (Mote et al. 2003), with great uncertainty in the prediction of precipitation in each season. Regional climate modeling studies (Payne et al. 2004, among others) show similar results. In general, the modeling results suggest a continuation of trends observed in the PNW during the 20th century (Mote 2003). One drawback in developing regional climate change predictions from climate models is the poor resolution of the models (IPCC 2001). Due to this and the climatic complexity of the PNW, it is important to understand the sub-regional variability of spatial patterns and temporal trends.

The PNW is typically defined as the states of Oregon, Washington, and Idaho, as well as the coastal parts of British Columbia and southeastern Alaska. However, in this study, we define the PNW as Oregon, Washington, and Idaho in their entirety, western Montana, northern California, and northern Nevada. Although it is outside the traditional boundaries of the PNW, northern Nevada is included in this study to demonstrate the similar precipitation regimes between adjacent physiographic regions (e.g. the Great Basin). Moreover, the climate divisions of northern Nevada are geographically similar to those of southeastern Oregon and southern Idaho. 
The complex terrain of the PNW drives much of the intra-regional climatology (Fig. 1). Areas west of the Cascades have a maritime climate with abundant winter precipitation and relatively dry summers. In this region, as much as $80 \%$ of the annual precipitation occurs between October and March. Areas east of the Cascades also have a winter wet and summer dry season, but absolute differences between winter and summer precipitation are generally smaller. In the lee of the Cascades, winter season (October-March) precipitation accounts for $50 \%$ to $70 \%$ of the annual total, considerably less than in the windward locations. In fact, cold season precipitation accounts for less than half of the annual precipitation in parts of southeastern Idaho and western Montana. However, elevation is an important control on the seasonality of precipitation east of the Cascades. For instance, some lowland locations have a trinomial distribution in precipitation. This demonstrates the intra-regional variability of precipitation regimes.

The hydrology of the PNW is greatly dependent on winter season precipitation. Tree growth is well correlated with the amount of winter season precipitation (Peterson \& Peterson 2001, Mote et al. 2003, Knapp et al. 2004), while the spring and summer streamflow that

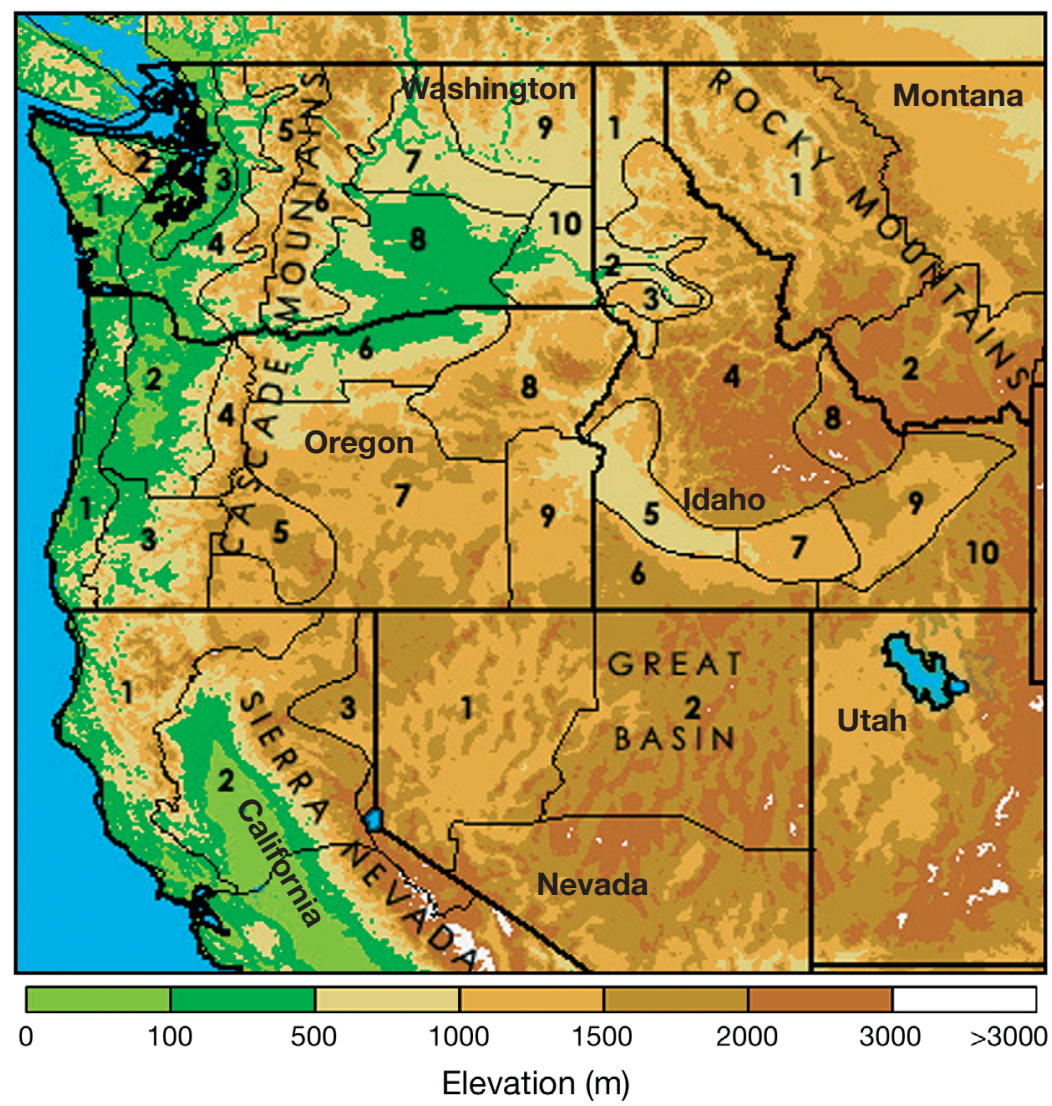

Fig. 1. Relief map of the Northwest USA with the 36 climate divisions used in the analysis numbered and outlined in black results from the melting snowpack is important for hydropower, irrigation and drinking water (Mote et al. 2003). There is also evidence that antecedent precipitation anomalies are correlated with anomalous summer fire activity, though this relationship varies regionally and temporally (Westerling et al. 2003, Westerling et al. 2006). However, there is considerable uncertainty about the relationship between summer fire activity and antecedent precipitation (Keeley 2004).

Two teleconnections drive much of the long-term precipitation variability in the PNW. Annual variability is largely controlled by the El Niño/Southern Oscillation (ENSO), which describes variability in the ocean and atmosphere of the tropical Pacific on a 3 to $7 \mathrm{yr}$ cycle. La Niña is associated with wet and cold winters in the PNW, while El Niño is associated with dry and warm winters (Redmond \& Koch 1991). While ENSO represents variability within the tropical ocean and atmosphere, the Pacific Decadal Oscillation (PDO) represents variability within the extratropical ocean and atmosphere. The PDO characterizes low frequency changes in sea surface temperatures (SST) in the Pacific Ocean with a period of roughly $50 \mathrm{yr}$ (Mantua et al. 1997). The warm (cold) phase of the PDO has a similar climatic effect on the PNW as El Niño (La Niña).

The longer term PDO may have the ability to 'modulate' the strength of the ENSO climate signal on winter precipitation, as suggested by Gershunov \& Barnett (1998), McCabe \& Dettinger (1999, 2002), Goodrich (2004), and others. The PDO is also linked to decadal drought patterns in the western United States (Hidalgo 2004, McCabe et al. 2004).

While the physical mechanisms behind ENSO have been well documented, there is still considerable uncertainty regarding the dynamics of the PDO as well as the complexity of its relationship to ENSO (Gutzler et al. 2002, Brown \& Comrie 2004). Miller \& Schneider (2000) outline several options for multidecadal variability in the north Pacific Ocean, which range from stochastic surface wind stress to tropical-extratropical interactions. Others have suggested that the PDO represents the ENSO signal plus red noise (Gedalof et al. 2002, Newman et al. 2003). More recently, Schneider \& Cornuelle (2005) suggested that the PDO is a function of the superposition of SST fluctuations emanating from dynamical modes such as ENSO and 
the Kuroshio-Oyashio Extension, among others. Regardless of the relationship between the PDO and ENSO, the usefulness of ENSO as a seasonal predictive tool does depend on the phase of the PDO. One goal of this study was to determine the extent of subregional variability between the impact of ENSO and the PDO on winter season precipitation in the PNW.

Principal Components Analysis (PCA) has often been used to investigate climate regionalization using either drought indices or precipitation data (Mitchell \& Blier 1997, Comrie \& Glenn 1998, Cook et al. 1999, Englehart \& Douglas 2002, Keyantash \& Dracup 2004, McCabe et al. 2004). The studies use PCA to understand the underlying spatial structure of the climate data. The component scores from the PCA can then be used to examine temporal trends within the given sub-regions.

This study consisted of 4 parts. (1) PCA was used to develop climatic sub-regions within the PNW based on regions of similar variance for winter season precipitation. (2) Synoptic climate analysis of each of the principal component (PC) regions was performed to demonstrate the physical efficacy of the resulting spatial patterns. (3) Time series of the component scores from the PCA for each sub-region were created to examine long-term trends. It has been suggested that the various sub-regions of the PNW, while experiencing significantly different absolute precipitation amounts, have a regional coherence in temporal variability (Mote et al. 2003). We test this assertion with a different methodological approach. The effects of ENSO and the PDO on sub-regional precipitation were examined to establish the great variability in teleconnection sensitivity within the greater PNW.

\section{DATA AND METHODS}

\subsection{Data}

\subsubsection{Precipitation}

This study considers the winter season in the PNW to occur from October through March. Climate division data used in this study were obtained online from the NOAA National Climatic Data Center (NCDC) (available at www.cdc.noaa.gov/Timeseries), and there were no missing data. Monthly October-March precipitation was summed for all the climate divisions of Washington, Oregon and Idaho, the northern 3 climate divisions of California, the northern 2 climate divisions of Nevada, and the 2 westernmost climate divisions of Montana for the years 1895-2003.

Each climate division represents a simple unweighted average from all representative stations within that division (Guttman \& Quayle 1996). While data from 1931 to the present were generated using the above method, from 1895-1930 a regression technique was used based on available United States Department of Agriculture (USDA) statewide averages, which has reduced the variance for these years (Guttman \& Quayle 1996). Because some researchers (Keim et al. 2003) have argued that the quality of the pre-1931 climate division data may introduce spurious long-term trends, all analyses were repeated using the subset of years 1931-2003 and only minor differences in sub-regions were found. Moreover, the component time series scores using the shorter period of record were basically unchanged from the PCA based on the complete dataset. Inhomogeneity issues regarding time-varying distributions of station data were reconciled by Gutzler et al. (2002).

While performing PCA on non-normal data has been shown to be acceptable in certain cases (Rummel 1970), the precipitation data were nevertheless analyzed for normality. Using standardized coefficients of skewness and kurtosis, we found that only 1 of 36 climate divisions had a significant deviation from normality (based on a 95\% confidence level). A square root transformation eliminated the significant deviation from normality. However, the results of the PCA were not substantially different whether raw or transformed data were used, as found in Comrie \& Glenn (1998).

\subsubsection{Teleconnections}

SST data from the Niño 3.4 region were used to represent ENSO. Niño 3.4 is an area bounded latitudinally $5^{\circ} \mathrm{N}$ and $\mathrm{S}$ of the equator and longitudinally between $120^{\circ}$ and $170^{\circ} \mathrm{W}$. A common method to determine various ENSO events is outlined in Trenberth (1997), and states that when the 5 mo moving average of Niño 3.4 anomalies exceeds $+0.4(-0.4)$ for 6 consecutive months, an El Niño (La Niña) is said to occur. The strongest lagged relationship between Niño 3.4 SSTs and winter precipitation in the western United States occurs from September to November (Harshburger et al. 2002). Therefore, ENSO events are classified by using the September-November averaged Niño 3.4 anomalies preceding the winter period. The ENSO values were split into 3 nearly equal groups with the warmest third classified as El Niño, the middle third as 'neutral' and the coldest third as La Niña. This classification produces a set of ENSO events that is similar to those obtained by using the method outlined in Trenberth (1997). The dataset used in this study is the Kaplan extended Niño 3.4 dataset (Kaplan et al. 1998), obtained online from the International Research 
Institute for Climate Prediction (IRI) data library (http://iridl.ldeo.columbia.edu/SOURCES/.Indices/.nino/ .EXTENDED/.NINO34/).

The PDO characterizes low frequency changes in SSTs in the Pacific Ocean with a period of roughly 50 yr. The PDO index is the leading principal component or eigenvector of the mean monthly SSTs in the Pacific Ocean north of $20^{\circ} \mathrm{N}$ latitude (Mantua et al. 1997). Positive values of the index refer to above normal SSTs along the west coast of North America and along the equator and below normal SSTs in the central and western North Pacific around $45^{\circ} \mathrm{N}$ latitude. Negative values of the index refer to the opposite distribution of SSTs in these same areas. According to Mantua et al. (1997) there have only been 3 complete phases of the PDO since 1925 (warm: 1925-1946 and 1977-1998, cold: 1947-1976). More recently, Mantua \& Hare (2002) established that the PDO was in the cold phase from 1890-1924. While some have speculated that the PDO may have shifted to a cold phase beginning in 1999 (Hare \& Mantua 2000, Schwing \& Moore 2000), most scientists agree that this may not be known for several years (Mantua \& Hare 2002, Chavez et al. 2003). In most of our PDO analyses, we categorized the PDO as either a 'warm' or a 'cold' event according to the yearly definitions noted above from Mantua et al. (1997). For the correlation analyses only, antecedent PDO values were used in a similar manner to the antecedent ENSO values described above. Certain analyses were truncated to 1998 because of the uncertainty of the current PDO phase after the strong 1997-98 El Niño event. The PDO dataset used in this study was obtained online from the Joint Institute for the Study of Atmosphere and Oceans (JISAO) at the University of Washington (http://jisao.washington.edu/ pdo/PDO.latest).

\subsubsection{NCEP reanalysis data}

To demonstrate that the regional precipitation patterns revealed by the PCA analysis are physically realistic, we examined synoptic atmospheric circulation patterns associated with wet and dry conditions in each PC region using $700 \mathrm{hPa}$ height data produced under the auspices of the NCEP Reanalysis Project (Kistler et al. 2001). The height data were downloaded from the Climate Diagnostics Center (CDC) (www.cdc. noaa.gov/) and cover the period 1949-2003. We selected the monthly $700 \mathrm{hPa}$ field, because this level is close to the average crest height in the western United States and is generally considered the most appropriate for weather analysis in this region (McCabe \& Legates 1995).

\subsection{Methods}

\subsubsection{PCA}

One goal of this study was to use PCA to identify groups of climate divisions in the PNW with similar variance structures that can be explained by synoptic mechanisms. Often, PCA is done on individual station data to determine climate regionalization (Woodhouse \& Kay 1990, White et al. 1991, Baeriswyl \& Rebetez 1997, Comrie \& Glenn 1998, Romero et al. 1999). However, the use of climate division data in PCA is also commonly employed (e.g. Mitchell \& Blier 1997, Chang \& Smith 2001, Gutzler 2004, Keyantash \& Dracup 2004, McCabe et al. 2004). Karl \& Koscielny (1982) demonstrated that performing PCA on nongridded data can lead to distorted loading patterns, but due to our prior knowledge of PNW climate, and the fact that this analysis groups climate divisions instead of creating contoured loading maps, problems with using non-gridded data should be avoided.

Because each climate division represents the unweighted monthly average of all representative stations within that division, our PCA placed climate divisions into several homogeneous groups. Like Comrie \& Glenn (1998), we used the correlation matrix, as opposed to the covariance matrix, to allow climate divisions under similar synoptic conditions to be grouped together. The assumption was made that all representative stations within each climate division share a similar temporal pattern of precipitation, even if total precipitation values are different. To test this, representative stations with long-term precipitation records from each climate division were selected and a PCA was conducted on this subset of stations. The subregions created by the PCA were comparable regardless of whether climate divisions or individual stations were used, and the resultant time series of the component scores were also similar.

After the initial PCA, 2 popular rotation methods were used to determine group membership of the climate divisions; orthogonal varimax and oblique (Direct Oblimin) with an obliquity parameter $\gamma=0$. Both rotations have been used in climate regionalization studies, with oblique rotation, which allows for slight correlation between vector swarms, often favored for its more realistic loading patterns and relationship with synoptic patterns (White et al. 1991, Comrie \& Glenn 1998). However, we found little difference between the 2 rotation methods and ultimately preferred the orthogonal solution, because it tends to preserve maximum loading of individual components (Cook et al. 1999, Frei \& Robinson 1999, McCabe et al. 2004). Finally, the Scree test (Cattell 1966) and eigenvalue separation test (North et al. 1982) were used to deter- 
mine the number of factors to retain from the PCA analysis. The maximum loading was used to determine group membership for each climate division.

\subsubsection{Synoptic climatology and PC regions}

Using National Center for Environmental Protection (NCEP) reanalysis atmospheric height data for 19492003, correlation maps demonstrating the relationship between PC seasonal precipitation and the concurrent $700 \mathrm{hPa}$ field were created. To show the physical representativeness of the climate regions, seasonal precipitation amounts from individual stations within each PC region were also correlated to $700 \mathrm{hPa}$ heights for winter season precipitation. Klein \& Bloom (1987) showed that the assumption of a linear relationship between seasonal height fields and precipitation is valid for diagnosing circulation patterns associated with anomalous conditions.

\subsubsection{PC region time series analysis}

Time series of the component scores were created to examine periods of anomalous precipitation during the 20th century for each of the PCA generated sub-regions for winter season precipitation. Each of the time series was smoothed with an 11 yr lowpass Gaussian filter to show decadal trends; other wavelengths ( 7 to $9 \mathrm{yr}$ ) were examined with little difference noted.

\subsubsection{Teleconnection analysis}

We performed a correlation analysis between the time series of the component scores and the ENSO and PDO indices to illustrate the variable nature of winter season teleconnectivity in the PNW sub-regions. Initially, we examined the effects of ENSO and PDO separately. Next, we analyzed the influence of PDO phase on ENSO in the manner of Gershunov \& Barnett (1998), Gutzler et al. (2002), and others. Finally, we examined how the relationship between precipitation and extreme values of ENSO and PDO for each of the sub-regions varies.

\section{RESULTS AND ANALYSES}

\subsection{Regions}

The orthogonal rotation produced 4 eigenvectors that met our selection criteria. Table 1 shows the variance explained for both the unrotated and varimax rotated eigenvectors. More than $83 \%$ of the variance in winter season precipitation is explained by the 4 eigenvectors.

As illustrated in Fig. 2, Region PC 1 (green) contains climate divisions that are considered the 'classic' Pacific Northwest spatial pattern comprising coastal Oregon and Washington, as well as the western valleys of both states. In addition, the eastern highlands of Washington and the northern tip of Idaho are included in Region 1. Overall, the wettest areas of the PNW are

Table 1. Unrotated and varimax rotated percent of variance $\left(\mathrm{s}^{2}\right)$ explained for the 4 dominant principal components of winter season (October-March) precipitation

\begin{tabular}{|c|c|c|c|c|c|c|}
\hline \multirow[b]{2}{*}{$\mathrm{PC}$} & \multicolumn{3}{|c|}{ Initial eigenvalues } & \multicolumn{3}{|c|}{ Rotation sums of squared loadings } \\
\hline & Eigenvalue & $\%$ of $s^{2}$ & Cumulative & Eigenvalue & $\%$ of $\mathrm{s}^{2}$ & Cumulative \\
\hline 1 & 21.4 & 59.4 & 59.4 & 10.0 & 27.9 & 27.9 \\
\hline 2 & 5.6 & 15.5 & 74.9 & 8.1 & 22.6 & 50.5 \\
\hline 3 & 1.9 & 5.2 & 80.1 & 6.6 & 18.3 & 68.8 \\
\hline 4 & 1.4 & 4.0 & 84.1 & 5.5 & 15.3 & 84.1 \\
\hline
\end{tabular}

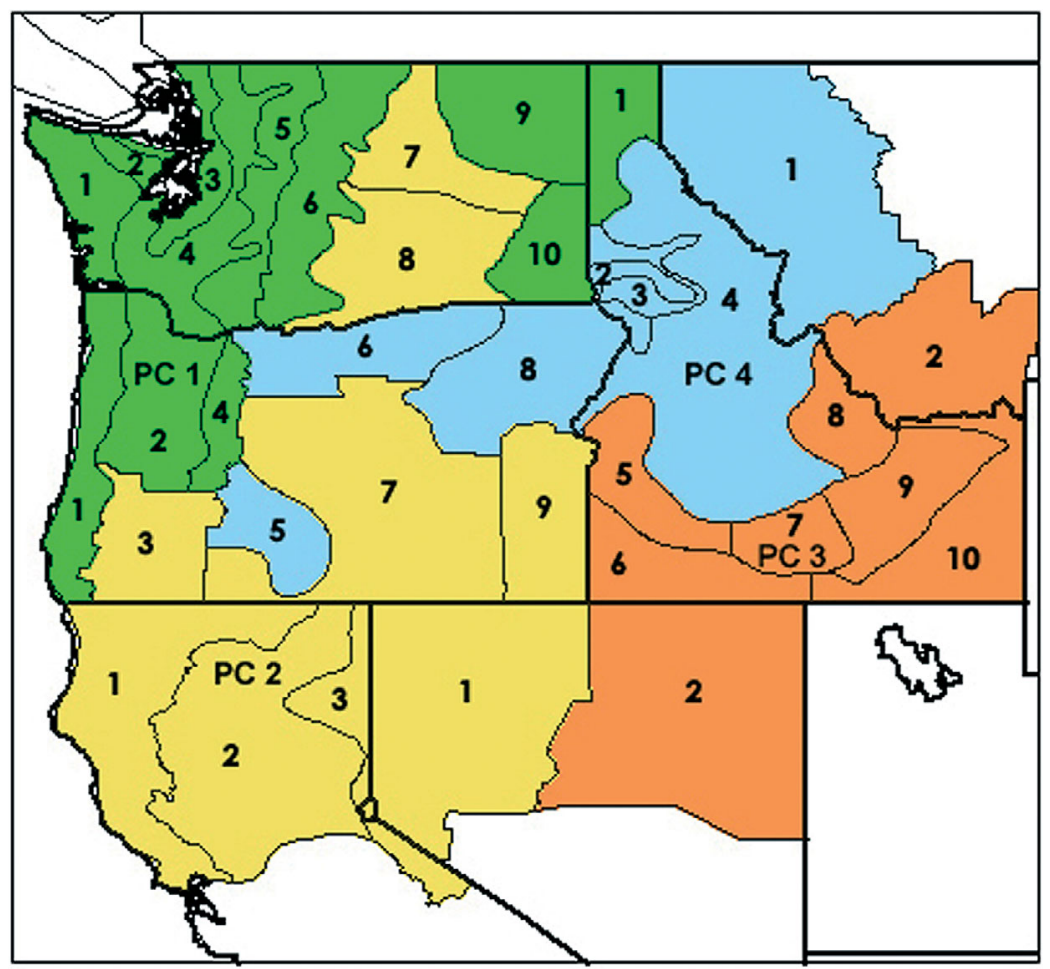

Fig. 2. Rotated varimax loadings of climate divisions for the 4 dominant principal components (PC 1-4 principal components) of October-March precipitation using the maximum loading rule 
contained within PC 1 with more than $1000 \mathrm{~mm}$ of precipitation averaged between October and March in half of the divisions representing this sub-region.

The sub-region identified by Region PC 2 (yellow) includes northern California, northwestern Nevada, southern Oregon, and central Washington. We were surprised by the spatial pattern in Region 2, most notably the common classification of central Washington and northern California. Due to this unexpected result, we carefully examined precipitation totals from Divisions CA 1 and WA 3, 5, 7 \& 8 for the 108 winters in the study. While there is a statistically significant relationship $\left(R^{2}=0.32\right)$ between winter season precipitation in WA 3 and WA 7, the correlation between CA 1 and WA $7\left(\mathrm{R}^{2}=0.55\right)$ precipitation is more robust (Fig. 3). In fact, each of the $3 \mathrm{CA}$ climate divisions is more significantly correlated to both WA 7 and WA 8 precipitation than either of these 2 WA divisions is correlated to any of the western Washington climate divi- sions. We also examined the correlation between representative stations located in each climate division and obtained similar results. In section 3.4 we present synoptic climate analyses that explain the statistical relationship between northern California and central Washington winter season precipitation.

Region PC 3 (brown) contains the valleys of the Snake River (Divisions ID 5, $7 \&$ 9) and northern Great Basin (Divisions NV 2 \& ID 6). Compared to the other PC regions, precipitation amount in Region PC 3 is more spatially homogenous. For instance, the wettest parts of the region, MT 2 and ID 10, receive approximately $400 \mathrm{~mm}$ of precipitation per year, while the driest parts receive about $275 \mathrm{~mm}$. Furthermore, precipitation is generally more evenly distributed throughout the year in Region PC 3 than in the other sub-regions.

Region PC 4 (blue) contains a complex array of climate divisions including the southern highlands of Oregon, eastern Oregon, central Idaho, and western Montana. As
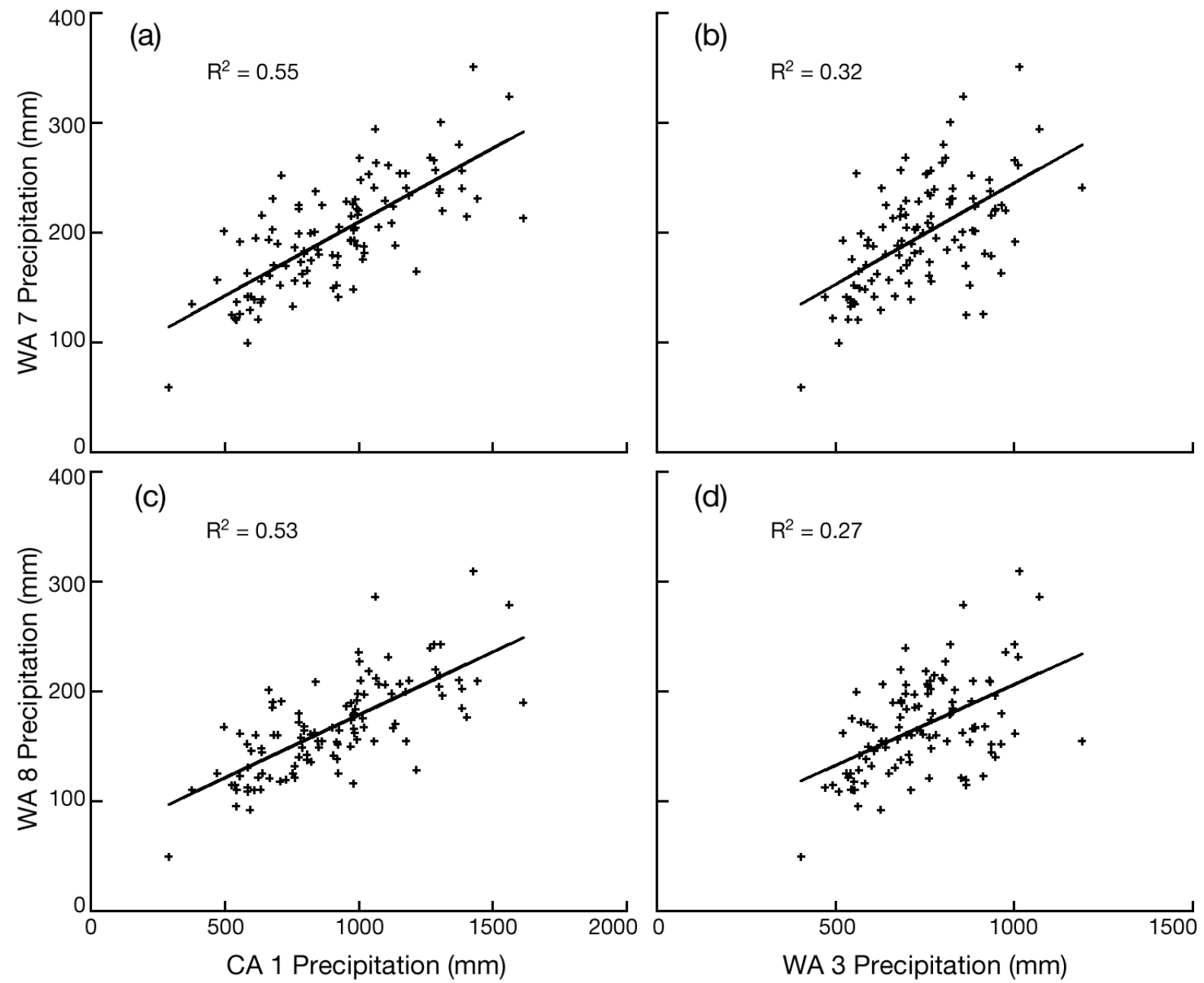

(d)

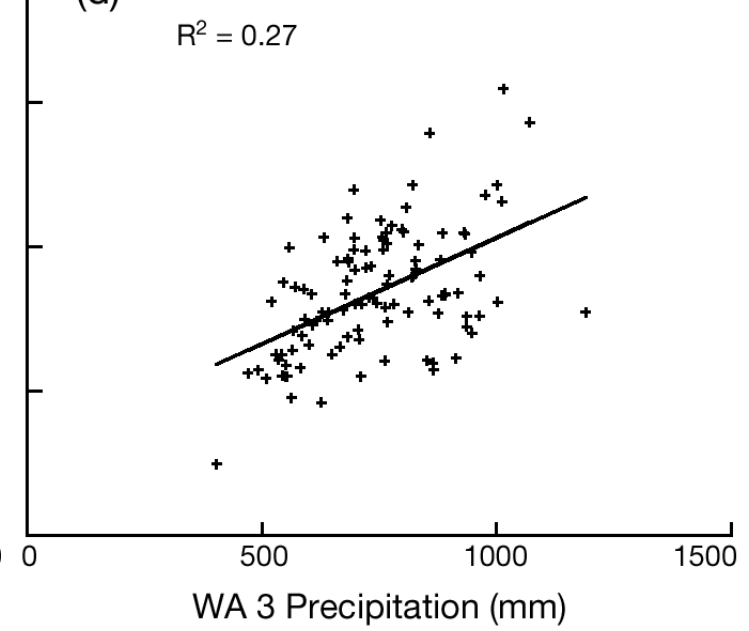

Fig. 3. Relationship between 1896-2003 winter season precipitation of climate divisions for: (a,c) northern California (CA 1) and central Washington (WA 7 \& WA 8); (b,d) relationship between Puget Sound (WA 3) and central Washington (WA 7 \& WA 8) 
shown in Fig. 1, Region PC 4 contains several significant mountain ranges exceeding $3000 \mathrm{~m}$ in elevation. Therefore, we classify Region PC 4 as the mountainous inland PNW given the topographic similarity between the climate divisions composing this sub-region.

\subsection{Correlation analysis}

The regionalization produced by the varimax rotation revealed physically realistic spatial patterns of seasonal precipitation. However, in some instances (e.g. Region PC 2) the regionalization was counterintuitive. In this section, we analyze the synoptic controls on precipitation in each of the 4 sub-regions. This analysis will demonstrate that each sub-region is physically realistic given the unique synoptic controls on winter season precipitation in each of the derived regions.

Fig. 4 illustrates the correlations between the October-March $700 \mathrm{hPa}$ height field and precipitation for each of the 4 PC regions. In Region PC 1, the 'classic'
PNW pattern, wet conditions are associated with anomalous cyclonic circulation centered over southeastern Alaska. This atmospheric pattern, which is spatially similar to the positive phase of the East Pacific Oscillation found by Barnston \& Livezey (1987), promotes west to southwesterly flow into coastal Oregon and Washington. The strength of the Aleutian Low is also an important control on precipitation in Region PC 1. In addition, PC 1 precipitation is positively correlated to $700 \mathrm{hPa}$ heights off the coast of Baja California, a characteristic unique to PC 1. Fig. 4 demonstrates that during dry winters in PC 1, southern California experiences anomalous cyclonic flow, which captures the well-documented inverse correlation between winter precipitation in southern California and the northwestern United States (Redmond \& Koch 1991).

Region PC 2 is the most spatially complex of our derived sub-regions containing climate divisions in northern California and central Washington that are separated by almost $1000 \mathrm{~km}$. We contend there is a logical explanation for the counterintuitive relation-
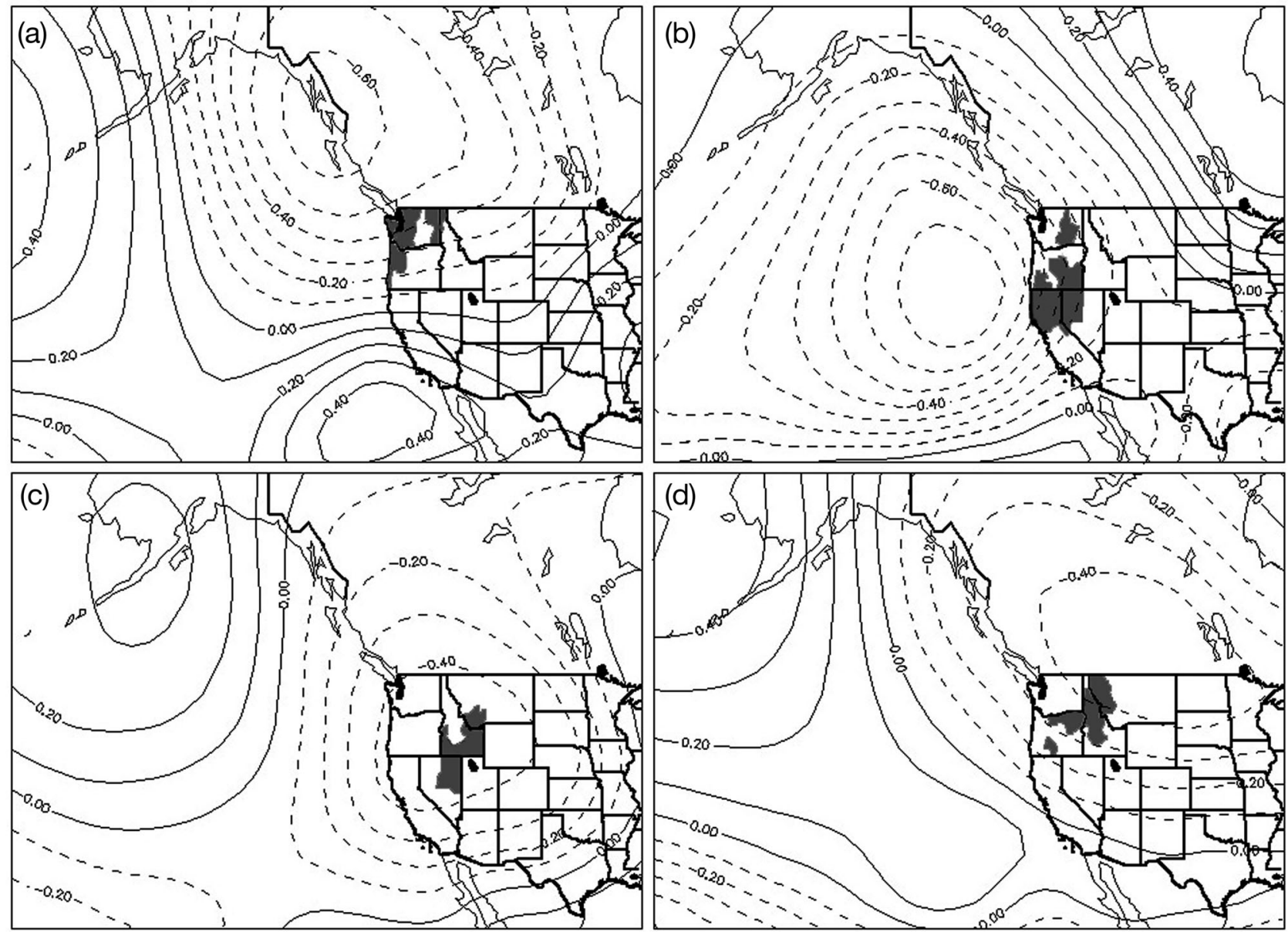

Fig. 4. Correlations between winter (October-March) mean $700 \mathrm{hPa}$ height anomalies and winter season precipitation in (a) PC 1;

(b) PC 2; (c) PC 3; (d) PC 4. Shaded areas represent each PC region. Positive correlations are indicated by solid isolines and negative correlations are indicated by dashed isolines: the isoline interval is 0.1 . The period of record is $1949-2003$ 
ship between northern California and central Washington winter precipitation. Wet winters in PC 2 occur in concert with anomalous cyclonic circulation centered off the coast of North America on the CaliforniaOregon border. This leads to enhanced southerly flow throughout the entire PC 2 region. In contrast, during wet winters in PC 1, central Washington is influenced by strong cross-barrier flow over the Cascades, leading to relatively dry conditions. However, central Washington experiences moisture advection from the south during anomalously wet winters in PC 2 . An increase in southerly flow reduces the desiccating effects of cross-barrier flow in central Washington. The correlation isolines indicate that anomalous southeasterly flow occurs in western Washington in association with wet winters in Region PC 2. This may lead to weak cross-barrier flow over the Cascades into the valleys of western Washington, promoting relatively dry conditions west of the mountains. Notably, precipitation in Region PC 2 is unrelated to the strength and position of the Aleutian Low, a unique feature among the sub-regions.

Unlike Regions PC 1 or 2, the center of maximum correlation in PC 3 occurs directly over the region. Wet winters in the Snake River Valley and northeastern reaches of the Great Basin (PC 3) are associated with anomalous cyclonic circulation over the western United States, a pattern that is spatially similar to the negative phase of the Pacific North American pattern (PNA) presented in Barnston \& Livezey (1987). In contrast, anomalous anticyclonic circulation over the western third of the United States tends to produce dry conditions. In general, a weakening of the Aleutian Low resulting in an eastern expansion of above normal $700 \mathrm{hPa}$ heights over the north Pacific leads to above normal precipitation.

Unique among the 4 sub-regions, winter season precipitation in PC 4 is linked to $700 \mathrm{hPa}$ heights in the central and south Pacific. Anomalously wet winters in the sub-region are generally associated with below normal $700 \mathrm{hPa}$ heights near Hawaii and over much of the North American continent. This correlation pattern also closely approximates the negative PNA pattern. While the center of maximum correlation is located west of each of the first 3 sub-regions, this feature is located northeast of PC 4. This suggests that anomalous cyclonic circulation to the lee of the Rocky Mountains is a primary characteristic of wet winters in the mountainous regions of the inland PNW.

We also examined correlation maps obtained by using precipitation data from representative meteorological stations in each climate division. In each case, the correlation patterns we found for representative stations in the derived regions closely matched the results in Fig. 4.

\subsection{Time series analysis}

Although the PNW is a relatively small geographic area, there are surprising sub-regional decadal scale trends in precipitation. Time series of the component scores were constructed for the 4 winter season eigenvectors (Fig. 5) to determine long-term trends in precipitation. An 11 yr Gaussian low-pass filter was applied to the time series data.

Fig. 5 reveals that 3 of the PC regions have experienced marked trends $(p<0.05)$ in winter season precipitation, as revealed by linear trend analysis. Only the second eigenvector describing the northern California, southern Oregon, and central Washington region shows no long-term trend. The coastal Oregon and Washington region described by PC 1 entered an anomalously wet period around 1990 with some of the wettest winters in the $108 \mathrm{yr}$ period occurring since this time. Conversely, the driest period in the instrumental record characterizes the period since 1980 in PC 4, the northern Rocky Mountains and northern Idaho region. Interestingly, the exact opposite trend was found in PC 3, the Snake River Plain region of southern Idaho, where winter precipitation has been consistently above normal since 1970. The trend toward extreme wet (dry) winters within the southern (northern) part of Idaho has not yet been documented in the literature.

\subsection{Teleconnection analysis}

When the PNW is viewed as a coherent region, it is generally assumed that winter season precipitation is negatively correlated with ENSO (Redmond \& Koch, 1991) and the PDO (Mantua et al. 1997). In other words, dry (wet) winters are associated with El Niño (La Niña) and the warm (cold) phase of the PDO. Table 2 shows

Table 2. Correlation of winter season principal component (PC) time series to atmospheric teleconnections and the mean winter season PC time series score for atmospheric teleconnection phases with significance values from $t$-test. Bold values are considered significant $(p<0.05)$

\begin{tabular}{|lrrrr|}
\hline & PC 1 & PC 2 & PC 3 & PC 4 \\
\hline Correlation coefficient (r) & & & & \\
Niño 3.4 & $\mathbf{- 0 . 2 5}$ & $\mathbf{0 . 2 3}$ & $\mathbf{- 0 . 2 2}$ & $\mathbf{- 0 . 4 0}$ \\
PDO & $\mathbf{- 0 . 3 1}$ & 0.11 & 0.04 & $\mathbf{- 0 . 2 9}$ \\
& & & & \\
Mean PC time series score & & & & \\
El Niño & -0.42 & 0.22 & -0.22 & -0.40 \\
La Niña & 0.25 & -0.25 & 0.31 & 0.57 \\
p & $\mathbf{0 . 0 1}$ & 0.07 & $\mathbf{0 . 0 1}$ & $\mathbf{0 . 0 1}$ \\
Warm PDO & -0.13 & -0.08 & 0.16 & -0.25 \\
Cold PDO & 0.03 & 0.07 & -0.09 & 0.26 \\
p & 0.40 & 0.46 & 0.21 & $\mathbf{0 . 0 1}$ \\
\hline
\end{tabular}



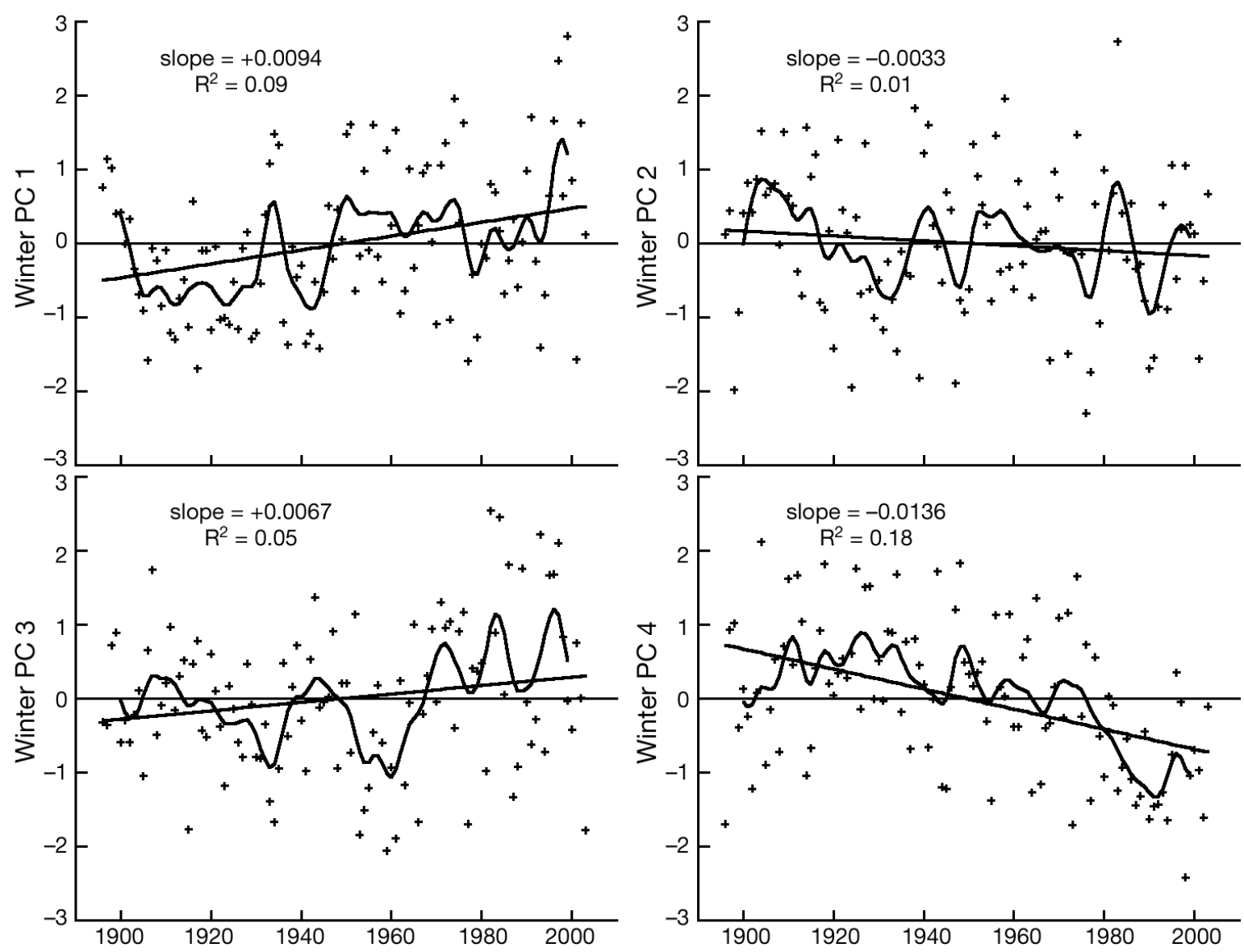

Fig. 5. Principal component (PC) score time series for each of the 4 regions. An 11 yr Gaussian low-pass filter and linear best-fit line was applied to the time series. The slope and $\mathrm{R}^{2}$ of the linear fit for each PC region is significant at $\mathrm{p}<0.05$ for all but PC 2

that when time series of the 4 winter season $\mathrm{PC}$ region component scores are correlated with ENSO and the PDO, there is significant sub-regional variability. PC 2, which is located in northern California and the rainshadow regions of Oregon and Washington, is positively correlated (El Niño - wet) with Niño 3.4 SST anomalies $(\mathrm{p}<0.05)$ while the other $3 \mathrm{PC}$ regions have the expected El Niño - dry relationship. Two regions (PC 2 and PC 3) show a weak positive correlation to the PDO but these results are not statistically significant.

Table 2 also represents a comparison of the mean component scores for each PC region for the various phases of ENSO and the PDO. The reciprocal relationship between El Niño and La Niña and winter season precipitation is statistically significant $(p<0.05)$ for 3 of 4 PC regions. PC 2 is the only one of the 4 PC regions in the PNW to have an El Niño - wet relationship, of which the physical mechanisms are alluded to in the correlation analysis presented in Section 3.2. It is also worth noting that while not shown, the neutral phase of ENSO has a mean component score near 0.0 in nearly all PC regions and represents the fulcrum of the seesaw relationship. This distinction becomes important when the influence of PDO phase on ENSO is considered later in this section. The warm and cold phases of the PDO have a similar relationship with winter season precipitation, but are only significant in PC 4, which is centered over the northern Rockies. When the influence of PDO phase on the relationship between El Niño, La Niña and neutral ENSO conditions and winter season precipitation is considered (Fig. 6), years of El Niño (La Niña) tend to be drier (wetter) than normal during the warm (cold) phase of the PDO. There is some visual evidence for PDO modulation during years of neutral ENSO as found in the Southwest USA by Goodrich (2004). Years of neutral ENSO during the warm (cold) PDO are slightly wetter (drier) than normal, although these differences are in most cases not statistically significant. A difference of means test for each of the 36 climate divisions comparing El Niño/warm PDO to El Niño/cold PDO shows that 8 of the 36 climate divisions were significantly different $(p<0.05)$. Most of these 8 climate divisions are located in the PC 4 region. 

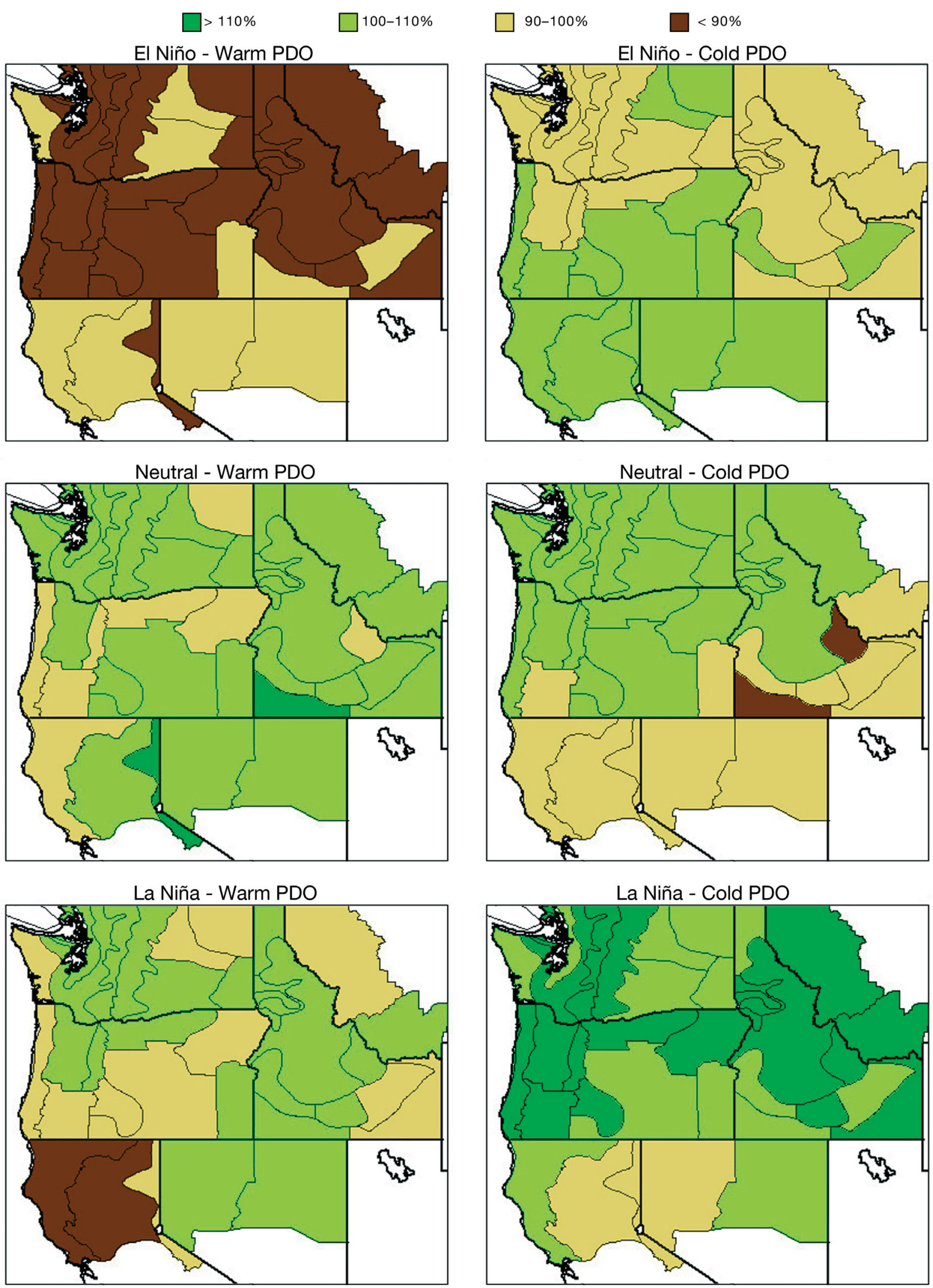

Fig. 6. Winter season precipitation relative to normal for ENSO/PDO combinations in the Pacific Northwest of the USA 
Table 3. Mean winter season principal component (PC) time series for ENSO/PDO combinations. Bold: $\mathrm{p}<0.05$; $t$-test between like ENSO phases (El Niño/warm PDO compared to El Niño/cold PDO etc.). n: number of yr

\begin{tabular}{|lrrrrr|}
\hline Winter season & PC 1 & PC 2 & PC 3 & PC 4 & n \\
\hline El Niño/Warm PDO & -0.48 & 0.05 & -0.27 & $\mathbf{- 0 . 8 2}$ & 14 \\
El Niño/Cold PDO & -0.38 & 0.34 & -0.19 & $\mathbf{- 0 . 1 1}$ & 20 \\
Neutral/Warm PDO & 0.07 & 0.00 & $\mathbf{0 . 3 9}$ & -0.17 & 19 \\
Neutral/Cold PDO & 0.04 & 0.12 & $\mathbf{- 0 . 5 7}$ & 0.13 & 16 \\
La Niña/Warm PDO & -0.02 & -0.37 & 0.30 & 0.33 & 11 \\
La Niña/Cold PDO & 0.38 & -0.19 & 0.32 & 0.68 & 23 \\
\hline
\end{tabular}

A similar test of La Niña years split by PDO phase yielded comparable but less significant results.

Table 3 is similar to Table 2 except that instead of showing the separate impacts of ENSO and PDO on mean component scores for the 4 PC regions, the modulation effect of PDO on ENSO is shown. The difference in mean PC score when years of El Niño are split into subsets of warm and cold PDO is significant $(\mathrm{p}<$ 0.05) in PC 4. Similar differences in mean PC scores emerge when years of neutral ENSO are split by PDO phase in PC $3(p<0.05)$. The variety of relationships between the PC regions and the 6 ENSO/PDO combinations for precipitation suggests that teleconnective relationships within the PNW are quite variable and more complex than a simple El Niño - dry (La Niña wet) relationship. ANOVA on the mean PC component scores also shows that all 4 PC regions (except PC 2) demonstrate a significant difference $(\mathrm{p}<0.05)$ between the ENSO/PDO combinations.

Finally, we ranked the Niño 3.4 SSTs and PDO index to determine the 15 highest and lowest values. Because winter season precipitation is so important hydrologically to the PNW, we were interested in how the sensitivity of precipitation to extreme ENSO and PDO events varies intra-regionally. Table 4 shows the mean component scores from each PC for the extreme values of El Niño and La Niña, as well as the high index values of the warm and cold PDO. These results can be compared with those of Table 2, which represents all years of the PDO and ENSO phases. Teleconnection sensitivity can best be understood here by whether or not the spread of the mean scores for a given teleconnection phase increases or decreases. For example, PC 4 has a spread of 0.97 (-0.40 for El Niño to 0.57 for La Niña) from Table 2 and a spread of 1.61 (-0.67 for El Niño to 0.94 for La Niña) from Table 4. Three of the 4 PC regions (all except PC 1) show an increased spread (more sensitivity) during high index ENSO values. In sum, as ENSO SST anomalies increase, the impact on precipitation becomes more anomalous in these regions. Moreover, sensitivity to the PDO increases dramatically for PC Regions 1 and 4.
Table 4. Mean winter season principal component (PC) time series for atmospheric teleconnection phase during the 15 highest and lowest index value events with significance values from $t$-test. Bold: $\mathrm{p}<0.05$

\begin{tabular}{|lrrrr|}
\hline & PC 1 & PC 2 & PC 3 & PC 4 \\
\hline El Niño & -0.14 & 0.34 & -0.29 & -0.67 \\
La Niña & 0.39 & -0.20 & 0.46 & 0.94 \\
p & 0.16 & 0.18 & $\mathbf{0 . 0 4}$ & $\mathbf{0 . 0 0}$ \\
Warm PDO & -0.48 & 0.38 & -0.14 & -0.76 \\
Cold PDO & 0.81 & 0.05 & 0.02 & 0.31 \\
p & $\mathbf{0 . 0 0}$ & 0.42 & 0.69 & $\mathbf{0 . 0 0}$ \\
\hline
\end{tabular}

PC 1, which demonstrates little relationship to PDO when all years are considered, exhibits a highly significant difference of means ( $p \ll 0.05$ ) for the smaller set of high index values. Years of high index cold PDO can be expected to be anomalously wet west of the Cascades in Washington and northern Oregon. The mean component scores suggest that high index years of cold PDO are a better predictor for wet winters than even La Niña for PC 1. Meanwhile PC 4, which has shown a high level of sensitivity to the PDO in nearly every test, also demonstrates a highly significant difference of means $(\mathrm{p} \ll 0.05)$ with very dry winters associated with years of high index warm PDO.

\section{CONCLUSIONS}

The goal of this study was to document intra-regional variability in winter season precipitation for the Pacific Northwest (PNW) and to examine the resultant time series of PC component scores for non-coherent trends; 4 sub-regions were revealed using rotated Principal Components Analysis (PCA) based on temporal variability of precipitation. While the winter season subregions were spatially similar, there were a few differences that derive from seasonal synoptic patterns. Although previous studies have suggested that the PNW shares a regional coherence in precipitation, our analyses of the time series of PC component scores, synoptic controls of precipitation, and teleconnection sensitivity of each sub-region suggests this may not be true. While the overall theme of the teleconnection analyses supports previous research (i.e. most of the PNW has an El Niño - dry relationship), we have demonstrated that there is significant spatial variability in teleconnective relationships between ENSO and PDO and precipitation that has not been explicitly expressed in the literature. The $4 \mathrm{PC}$ regions representing intra-regional variability in the PNW exhibit unique characteristics in winter season precipitation.

The one sub-region of the PNW that identified most closely to the traditional definition of the region was 
PC 1. This region, which consists primarily of Washington and northern Oregon from the windward slopes of the Cascades to the Pacific Ocean, displayed expected ENSO and PDO relationships (El Niño - dry and warm PDO - dry) and had synoptic controls that are spatially similar to that of the East Pacific Oscillation (EPO). It comes as no surprise that the consecutive rainfall records set in January 2006 in this sub-region coincided with anomalously high values of the EPO. While the climate of PC 1 is often said to represent the entire region, the results in this study suggest that 3 other climatically distinct sub-regions exist in the PNW. Northern California as well as the leeward sections of Washington and Oregon comprise PC 2, which has an opposite teleconnective relationship to ENSO and PDO (El Niño - wet and warm PDO - wet) compared to any other sub-regions and has synoptic controls spatially similar to that of the Pacific North American pattern. The final 2 sub-regions (PC 3 and PC 4) consist of the Rocky Mountains from northern Nevada to Idaho and western Montana and are split roughly along the Snake River plain. Although these final 2 regions are teleconnectively similar to winter PC 1 , they are both synoptically more similar to winter PC 2 .

In fact, the 2 Rocky Mountain sub-regions show widely diverging temporal trends in winter season precipitation over the past $30 \mathrm{yr}$, a timeframe that coincides with increased warming across the PNW. While climate regionalizations that use rotated PCA are always open to interpretation, we subjected the sub-regions to a number of tests that included comparison of individual stations in the sub-regions, examination of time series of PC component scores, computation of synoptic correlations with upper air data, and teleconnection sensitivity. We feel that these results suggest that the assumption of coherency in the climate signal of the Pacific Northwest is not valid and that further climate modeling of climate change in the region must take these differences into account.

\section{LITERATURE CITED}

Baeriswyl PA, Rebetez M (1997) Regionalization of precipitation in Switzerland by means of principal components analysis. Theor Appl Clim 58:31-41

Barnston AG, Livezey RE (1987) Classification, seasonality and persistence of low-frequency atmospheric circulation patterns. Mon Weather Rev 115:1083-1126

Brown DP, Comrie AC (2004) A winter precipitation 'dipole' in the western United States associated with multidecadal ENSO variability. Geophys Res Lett 31:L09203, doi:10.1029/ 2003GL018726, 2004

Cattell RB (1966) The scree test for the number of factors. Multivar Behav Res 1:245-276

Chang FC, Smith EA (2001) Hydrological and dynamical characteristics of summertime droughts over U.S. Great Plains. J Clim 14:2296-2316
Chavez FP, Ryan J, Lluch-Cota SE, Niquen M (2003) From anchovies to sardines and back: multidecadal change in the Pacific Ocean. Science 299:217-221

Comrie AC, Glenn EC (1998) Principal components-based regionalization of precipitation regimes across the southwest United States and northern Mexico, with an application to monsoon precipitation variability. Clim Res 10: 201-215

Cook ER, Meko DM, Stahle DW, Cleaveland MK (1999) Drought reconstructions for the continental United States. J Clim 12:1145-1162

Englehart PJ, Douglas AV (2002) On some characteristic variations in warm season precipitation over the central United States (1910-2000). J Geophys Res 107:4286, doi:10.1029/2001JD000972

Frei A, Robinson DA (1999) Northern hemisphere snow extent: regional variability 1972-1994. Int J Climatol 19: 1535-1560

Gedalof Z, Mantua NJ, Peterson DL (2002) A multi-century perspective of variability in the Pacific Decadal Oscillation: new insights from tree rings and coral. Geophys Res Lett 29:2204, doi:10.1029/2002GL015824

Gershunov A, Barnett TP (1998) Interdecadal modulation of ENSO teleconnections. Bull Am Meteorol Soc 79: 2715-2725

Goodrich GB (2004) Influence of the Pacific Decadal Oscillation on Arizona winter precipitation during years of neutral ENSO. Weather Forecast 19:950-953

Guttmann NB, Quayle RQ (1996) A historical perspective of U.S. climate divisions. Bull Am Meteorol Soc 77: 293-303

Gutzler DS (2004) An index of interannual precipitation variability in the core of the North American Monsoon region. J Clim 17:4473-4480

Gutzler DS, Kann DM, Thornbrugh C (2002) Modulation of ENSO-based long-lead outlooks of southwestern US winter precipitation by the Pacific Decadal Oscillation. Weather Forecast 17:1163-1172

Hamlet AF, Lettenmeier DP (1999) Effects of climate change on hydrology and water resources in the Columbia River Basin. J Am Water Resour Assoc 35:1597-1623

Hare SR, Mantua NJ (2000) Empirical evidence for North Pacific regime shifts in 1977 and 1989. Prog Oceanogr 47: 103-146

Harshburger B, Ye H, Dzialoski J (2002) Observational evidence of the influence of Pacific SSTs on winter precipitation and spring stream discharge in Idaho. J Hydromet 264:157-169

Hidalgo HG (2004) Climate precursors of multidecadal drought variability in the western United States. Water Resour Res 40:W12504

IPCC (Intergovernmental Panel on Climate Change) (2001) Climate change 2001: the scientific basis. Contribution of Working Group I to the Third Assessment Report of the Intergovernmental Panel on Climate Change. Cambridge University Press, Cambridge

Kaplan A, Cane M, Kushnir Y, Clement A, Blumenthal M, Rajagopalan B (1998) Analyses of global sea surface temperature 1856-1991. J Geophys Res 103:18567-18589

Karl TR, Koscielny AJ (1982) Drought in the United States 1895-1981. J Climatol 2:313-329

Keeley JE (2004) Impact of antecedent climate on fire regimes in coastal California. Int J Wildland Fire 13:173-182

Keim BD, Wilson AM, Wake CP, Huntington TG (2003) Are there spurious temperature trends in the United States Climate Division database? Geophys Res Lett 30:1404, doi:10.1029/2002GL016295, 2003 
Keyantash JA, Dracup JA (2004) An aggregate drought index: assessing drought severity based on fluctuations in the hydrologic cycle and surface water storage. Water Resour Res 40:W09304, doi:10.1029/2003WR002610,2004

Kistler R, Kalnay E, Collins W, Saha S and 9 others (2001) The NCEP-NCAR 50-year reanalysis monthly means CD-ROM and documentation. Bull Am Meteorol Soc 82:247-267

Klein WH, Bloom HJ (1987) Specification of monthly precipitation over the United States from the surrounding $700 \mathrm{mb}$ height field. Mon Weather Rev 115:2118-2132

Knapp PA, Soule PT, Grissino-Mayer HD (2004) Occurrence of sustained droughts in the interior Pacific Northwest (AD 1733-1980) inferred from tree-ring data. J Clim 17: $140-150$

Mantua NJ, Hare SR (2002) The Pacific Decadal Oscillation. J Oceanogr 58:35-44

Mantua NJ, Hare SR, Zhang Y, Wallace JM, Francis RC (1997) A Pacific interdecadal climate oscillation with impacts on salmon production. Bull Am Meteorol Soc 78:1069-1079

McCabe GJ, Dettinger MD (1999) Decadal variations in the strength of ENSO teleconnections with precipitation in the western United States. Int J Climatol 19:1399-1410

McCabe GJ, Dettinger MD (2002) Primary modes and predictability of year-to-year snowpack variations in the western United States from teleconnections with Pacific Ocean climate. J Hydromet 3:13-25

McCabe GJ, Legates DR (1995) Relationships between $700 \mathrm{hPa}$ height anomalies and 1 April snowpack accumulations in the western USA. Int J Climatol 15:517-530

McCabe GJ, Palecki MA, Betancourt JL (2004) Pacific and Atlantic Ocean influences on multidecadal drought frequency in the United States. Proc Natl Acad Sci USA 101: 4136-4141

Miles EL, Snover AK, Hamlet AF, Callahan B, Fluharty D (2000) Pacific Northwest regional assessment: the impacts of climate variability and climate change on the water resources of the Columbia River Basin. J Am Water Resour Assoc 36:399-420

Miller AJ, Schneider N (2000) Interdecadal climate regime dynamics in the North Pacific Ocean: theories, observations and ecosystem impacts. Prog Oceanogr 47: 355-379

Mitchell TP, Blier W (1997) The variability of wintertime precipitation in the region of California. J Clim 10: 2261-2276

Mote PW (2003) Trends in temperature and precipitation in

Editorial responsibility: Robert Davis,

Charlottesville, Virginia, USA the Pacific Northwest during the twentieth century. Northwest Sci 77:271-282

Mote PW, Parson EA, Hamlet AF, Ideker KN and 8 others (2003) Preparing for climate change: the water, salmon, and forests of the Pacific Northwest. Clim Change 61: $45-88$

Newman M, Compo GP, Alexander MA (2003) ENSO-forced variability of the Pacific decadal oscillation. J Clim 16: 3853-3857

North GR, Bell TL, Cahalan RF, Moeng FJ (1982) Sampling errors in the estimation of empirical orthogonal functions. Mon Weather Rev 110:699-706

Payne JT, Wood AW, Hamlet AF, Palmer RN, Lettenmaier DP (2004) Mitigating the effects of climate change on the water resources of the Columbia River Basin. Clim Change 62:233-256

Peterson DW, Peterson DL (2001) Mountain hemlock growth responds to climatic variability at annual and decadal time scales. Ecology 82:3330-3345

Redmond KT, Koch RW (1991) Surface climate and streamflow variability in the western United States and their relationship to large-scale circulation indices. Water Resour Res 27:2381-2399

Romero R, Ramis C, Guijarro JA (1999) Daily rainfall patterns in the Spanish Mediterranean area: an objective classification. Int J Climatol 19:95-112

Rummel RJ (1970) Applied factor analysis. Northwestern University Press, Evanston

Schneider N, Cornuelle BD (2005) The forcing of the Pacific Decadal Oscillation. J Clim 18:4355-4373

Schwing F, Moore C (2000) A year without a summer for California, or a harbinger of a climate shift? EOS Trans Am Geophys Union 81:301-305

Trenberth KE (1997) The definition of El Niño. Bull Am Meteorol Soc 78:2771-2777

Westerling AL, Gershunov A, Brown TJ, Cayan DR, Dettinger MD (2003) Climate and wildfire in the western United States. Bull Am Meteorol Soc 84:595-604

Westerling AL, Hidalgo HG, Cayan DR, Swetnam TW (2006) Warming and earlier spring increases western U.S. wildfire activity. Science 313:940-943

White D, Richman M, Yarnal B (1991) Climate regionalization and rotation of principal components. Int J Climatol 11:1-25

Woodhouse CA, Kay PA (1990) The use of tree-ring chronologies to show spatial and temporal changes in an air-mass boundary. Phys Geog 11:172-190

Submitted: April 3, 2006; Accepted: December 5, 2006

Proofs received from author(s): March 9, 2007 